\title{
Opposition to the European Union in the UK: The Dilemma of Public Opinion and Party Management
}

THE MAIN AIM OF THIS ARTICLE IS TO UNDERSTAND SOME OF THE processes at work in the management of European policy formation by political parties in the UK. ${ }^{1}$ More specifically, it attempts to apply and extend the model proposed by Aspinwall of institutional constraints on that policy management. ${ }^{2}$ Whereas Aspinwall limits the application of his model to parliamentary coalitions and effective power, we push the model further by describing and analysing its interaction with other features of the political landscape, most notably the generally low level of interest in European affairs on the part of the British public.

For almost all of the post-war period, the question of 'Europe' has been one that has occupied the minds of British legislators and governments. ${ }^{3}$ But the temptation for most commentators to concentrate on cultural and historical explanations of 'otherness' in the British case has resulted in a neglect of the more practical effects of institutional structures. This article addresses some of those effects by first providing a brief overview of Aspinwall's model, which suggests that the first-past-the-post (FPP) system creates centrifugal forces within the party system, resulting in parties holding compromise policy positions. This is followed by a discussion of the

${ }^{1}$ Thanks are due to Stephen George, Mark Aspinwall, Paul Taggart, Jo Waller and those at the presentation of this paper at the Political Studies Association 51st Conference, Manchester, 10-12 April 2001. Any inaccuracies which remain should be attributed to the author.

${ }^{2}$ See M. Aspinwall, 'Structuring Europe: Powersharing Institutions and British Preferences on European Integration', Political Studies, 48:3 (2000), pp. 415-42.

${ }^{3}$ Useful starting points on this topic include S. George, An Awkward Partner: Britain in the European Community, Oxford, Oxford University Press, 1998; and H. Young, This Blessed Plot: Britain and Europe from Churchill to Blair, Woodstock, Overlook Press, 1998. 
relative lack of interest among the public towards European integration as a political issue. As we will see, this lack of interest creates a situation in which party tensions may produce a more optimal policy position on European integration (although this is clearly dependent on the spread of public opinion), but will also result in sub-optimal policy positions vis-à-vis the electorate in other, and what are seen as more important policy areas. This results in a dilemma for party managers, forcing them to balance the requirement of party cohesion (since each party contains a variety of positions on policy) with the need for vote-maximization (since a more extreme policy position on Europe could potentially cost votes, both directly and indirectly). It is in the attempts to resolve this dilemma that a process of externalization occurs.

This externalization sees the more extreme elements within political parties using non-party groups as a means of better representing their opposition to European integration. This also has beneficial short-term effects for party managers, as it reduces intra-party conflicts. However, it also results in a radicalization of the opposition, as the controlling moderation of the party is removed. In the long term, it is argued, this has a negative feedback into both sides of the original dilemma, with party cohesion becoming more difficult, as the extreme elements pull the span of policy positions even wider, at the same time that public opinion becomes more mobilized.

\section{BRITISH PARTY STRUCTURES}

The starting point for our argument evolves from certain observations of the structure of the British party system, which has a built-in tendency to create movement away from a centrist position towards European integration. To understand this process, we will use the historical institutionalist model proposed by Aspinwall to look at British decision-making structures.

Rejecting historical experience and domestic economic and social interests as inadequate for explaining British attitudes towards the EU, Aspinwall proposes that it is the British electoral system that decisively shapes policy. Given that the UK is not alone in having a 'vocal minority hostile to European integration' among its electorate, the classic idea of 'British exceptionalism' derives from the domestic power-sharing institutions that 'channel pro- and anti-European 
sentiment in a fundamentally different way than in other member states'. ${ }^{4}$

Aspinwall structures attitudes towards European integration within political parties on a cleavage between a pro-integration core and an anti-integration fringe, which builds its opposition on a wide variety of reasons, drawing from both the left and right of the political spectrum. ${ }^{5}$ Such a modelling of attitudes reflects work by Hix and Lord and Taggart, who have stressed the transnational dimension of party positions on European integration, over and above national specificities. ${ }^{6}$ With this structure of attitudes set up, Aspinwall then suggests that the electoral system acts as the key intervening variable between social preferences and policy outcomes.

Under the FPP system, small parties are penalized and there is a strong incentive for prospective candidates to seek membership of one of the two main parties if they wish to have a reasonable chance of success. Once in the party, the members of the parliamentary party are kept in line by the Whip system. At the same time the party leadership has to accommodate those members with anti-integration opinions to a greater or lesser extent. Hence, "power sharing occurs within the ruling party, and on questions of European policy the centre of balance falls between the pro-integration centre of the spectrum and the anti-integration end of the spectrum' ${ }^{7}$

Aspinwall characterizes this tension as 'fundamentally anticentrist', since it creates a tension towards a polarizing of policy between the two parties. ${ }^{8}$ This echoes Finer's argument that the centrifugal forces within the system create not only a divergence from the overall attitude of Parliament but also, and more importantly, an even larger divergence from the overall attitude of the electorate as a whole, a point discussed in the next section. ${ }^{9}$ It stands in sharp contrast to the proportional representation (PR) electoral model, where while it is easier for those on the fringes to gain election, it is

${ }^{4}$ M. Aspinwall, op. cit., p. 416.

${ }^{5}$ Ibid., pp. 428-30.

${ }^{6}$ S. Hix and C. Lord, Political Parties in the EU, London, Macmillan; 1997; P. Taggart, 'A Touchstone of Dissent: Euroscepticism in Contemporary Western European Party Systems', European Journal of Political Research, 33:3 (1998), pp. 36388.

${ }^{7}$ M. Aspinwall, op. cit., p. 431. Also see Figure 4.

${ }^{8}$ Ibid.

${ }^{9}$ S. E. Finer, Adversary Politics and Electoral Reform, London, Anthony Wigram, 1975 . 
harder for them to enter into a governing (centrist) coalition. Thus anti-integrationists on both left and right tend to be excluded and marginalized from policy-making. ${ }^{10}$

The anti-centrist tendencies of the FPP system in the UK stretch beyond this key dynamic and are further modulated by structural constraints, the most important of which are the extent to which policy proposals affect national authority and the size of the government's majority. ${ }^{11}$ These essentially cover the linked matters of the likelihood of a backbench rebellion and the potential impact. As the government's majority falls, so too does the threshold for a proposal to be considered a threat to national authority, since the leverage that each individual MP has grows with a diminishing government majority. This effect is heightened by the increased likelihood that the smaller number of MPs required to overturn the government majority will have a common interest to pursue.

Why should it be that European integration, rather than any other issue, is seen as the dominant issue to have caused these tensions? The answer lies in the nature of the developing European system as a potential replacement for the national system. Matters such as health, education and taxation all provoke much debate, but they still reside within the existing national framework. However, with the creation of the European Union, a new arena has been opened up, in competition with the existing Westminster model. Westminster MPs have not only abstract concerns about the merits of the EU but also more self-interested concerns about their own powers. Their power to extract themselves from decisions made at the European level is limited, both by Parliament's limited power in everyday European decision-making and by the high costs associated with reversals on agreements and replacement strategies. ${ }^{12}$

Furthermore, the sheer speed of the Union's evolution since 1957 has created a rapid succession of specific issues to be considered and decided upon. From the 1975 referendum, to the budgetary question of the early 1980s, to Maastricht, to the euro, the list has

${ }^{10}$ M. Aspinwall, op. cit., p. 432.

${ }^{11}$ Ibid., p. 433.

${ }^{12}$ P. Norton, 'The United Kingdom: Political Conflict, Parliamentary Scrutiny', in P. Norton (ed.), National Parliaments and the European Union, London, Frank Cass, 1996, pp. 92-109, discusses parliamentary powers and their relation to the government. 
been nigh-on endless. Baker and his co-authors compare the internal divisions in the Conservative Party over European integration to the experiences of Chamberlain's tariff reforms and Peel's repeal of the Corn Laws. ${ }^{13}$ And it should not be forgotten that the Labour Party has had almost as much internal conflict on the matter as the Conservatives - the 1975 referendum campaign being a case in point. ${ }^{14}$

These combined factors have driven the EU to the foreground and have simultaneously suppressed other issues. As divisions on the European dimension were enhanced, so they tended to take precedence over other policy differences. The rising profile of the issue made it more important for MPs to be identified by their position regarding it, which in turn raised further awareness.

In summary, Aspinwall provides us with a process that generates certain tensions within the British political system. First, there is the tension within parties to accommodate the diversity of positions on integration, created by the need to have party unity in order to control Parliament. Secondly, there is the centrifugal force that the first tension creates, which pushes party policy away from the notional centre of Parliament's attitudes towards integration. Since we see opposition as being constructed on a centre-fringe model, any movement away from the centre implies an increase in opposition. This potential for anti-integrationist policy outcomes is further heightened when there is a small government majority in Parliament.

There have been two distinct periods since 1973 when this has been the case and in both we find that tensions over European policy have been heightened. The mid- to late-1970s saw first the pushing through of the renegotiation deal in the 1975 referendum against a background of internal party splits in both Labour and the Conservatives, followed by the decision on ERM membership in 1979, which rested on the need to preserve the pact between Labour and the Liberals. ${ }^{15}$ Thatcher's European policy was driven by external

${ }^{13}$ D. Baker, A. Gamble and S. Ludlam, '1846 . . 1906 . . . 1996? Conservatives and European Integration', Political Quarterly, 64:4 (1993), pp. 420-34.

${ }^{14}$ D. Butler and U. Kitzinger, The 1975 Referendum, London, Macmillan, 1976, is the best account of this event.

${ }^{15}$ See M. Aspinwall, op. cit., p. 434, Butler and Kitzinger, op. cit., and P. Ludlow, The Making of the European Monetary System, London, Butterworth, 1982, for discussions of these events. 
factors (e.g. the budget and the internal market), rather than by party divisions. The lack of parliamentary activity surrounding the ratification of the Single European Act in 1987 is indicative of this. ${ }^{16}$

While John Major experienced various difficulties during the Maastricht Intergovernmental Conferences of 1991, even though the party's majority was still sizeable, it was as nothing to the events during the 1992-97 Parliament. Holding a wafer-thin majority, the Conservatives became deeply divided over European issues both large (e.g. Maastricht ratification) and relatively small (e.g. the vetoing of the appointment of Jean-Luc Dehaene as Commission president). ${ }^{17}$

The outcome of all of this is that we see a political system which structures and drives centrifugal forces in the debate over European integration. On one hand, we might see this as a reasonable reflection of the importance of the European Union as a major innovation in the British and European system of governance. On the other, we might see it as a potentially very difficult problem for party managers to deal with, not least because of the role and profile of the European Union in public opinion. As much as the political system generates conflict and a raised profile for 'Europe', so public opinion has been markedly more ambivalent on the matter, as we shall see in the following section.

\section{'EUROPE' AS AN ISSUE}

Moving from parties' to the public's attitudes towards European integration we should remark on two elements. First, the distribution of preferences within the public at large can be argued to be one marked not by two peaks of pro and anti, but rather by widespread indifference or uncertainty. The Eurobarometer surveys run by the Commission provide a good source of data on this matter, in particular on people's attitudes towards membership. ${ }^{18}$ Figures giving

${ }^{16}$ The government guillotined the debating time, to little protest. See H. Young, This Blessed Plot, pp. 334-5, for more details.

${ }^{17}$ See M. Sowemimo, 'The Conservative Party and European Integration 198895', Party Politics, 2:1 (1996), pp. 77-97, and H. Young, op. cit.

${ }^{18}$ The relevant question reads: 'Generally speaking, do you think (our country's) membership of the European Union is ... (a good thing/a bad thing/neither good nor bad)?'. Full details are available at Eurobarometer's website: http://www. europa.eu.int/comm/dg10/epo/polls.html 
unequivocal opinions, both for and against membership, have seen very large shifts over the period since 1973, while those for 'neither good nor bad' and 'don't know' have been relatively static. While it could be argued that there is a general preference against integration, the size of the shifts points towards concluding that any such preferences are shallow and highly susceptible to active leadership by parties or other groups. The turnaround in the 1975 referendum campaign is a case in point.

This also leads us to the second element, namely the importance of the issue for the public. Since the United Kingdom joined in 1973 this has been highly variable. From effectively being a non-issue in the mid-1980s to the fairly substantial levels of interest in the late 1990 s, there has not been any real consistency. This variability has been further complicated by the relationship between support for membership and public opinion.

Since 1974, MORI has regularly asked its interviewees what they consider to be the most important issue, or issues, facing the country. ${ }^{19}$ The percentage of people giving 'the EC/EU' as one of those issues is shown in Figure 1 below. As can clearly be seen, there

Figure 1

Percentage of British People Feeling that the EC/EU is an Important Issue, 1974-2001

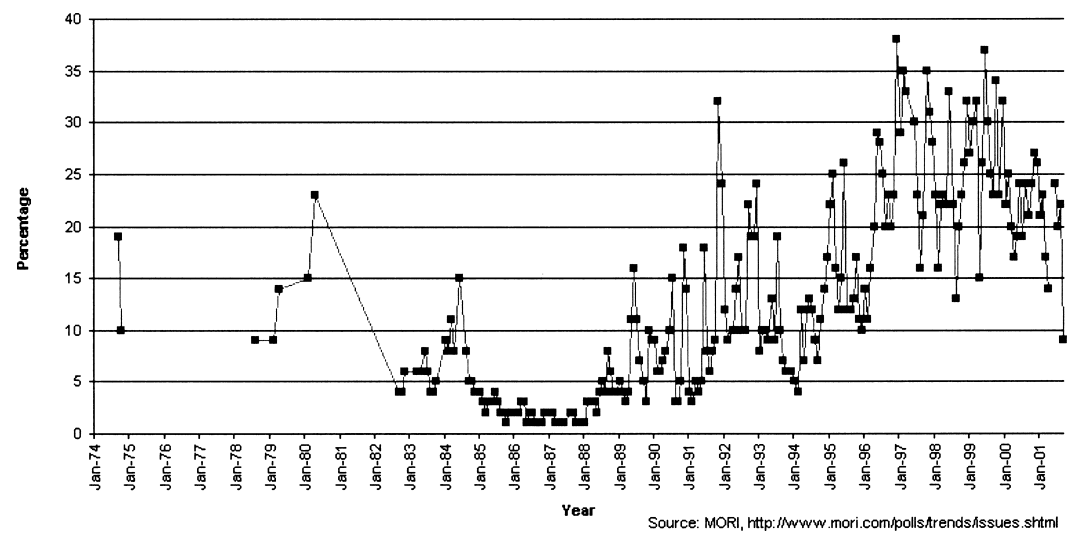

${ }^{19}$ A summary table is available at http://www.mori.com/polls/trends/ issues.shtml. The question reads: 'What do you see as the most important issue facing Britain today? What do you see as other important issues facing Britain today?'. Answers are unprompted and combined to form Table 1. 
is little regularity in the data, either in the long or the short term. Figures change sharply from one month to the next, even in periods of generally high percentages. Indeed, the only period of relatively consistent figures comes between 1985 and 1988, when the issue barely registered on the scale.

However, simply showing the percentage figures for the EC/EU as an important issue does not give a complete picture, since it ignores the relative importance with relation to other issues. In terms of its ranking in the MORI polls, again we can see that the issue has moved in and out of people's world-views over time. In Figure 2, which gives the issue its rank for each survey, there is a repetition of the movement seen in Figure 1.

Figure 2

Rank of EC/EU in Important Issues Facing Britain, 1974-2001 (Inverted Scale)

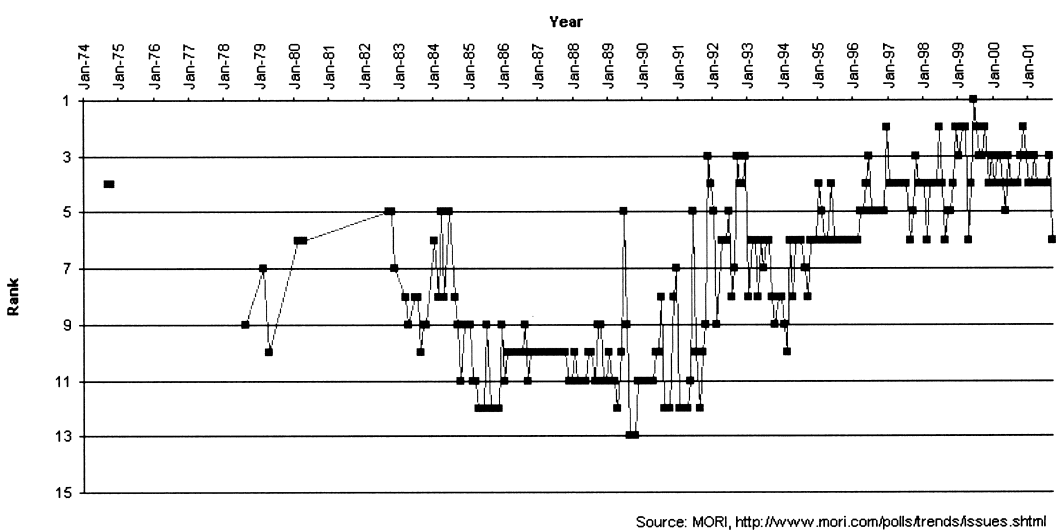

While both Figures 1 and 2 give the impression of a general increase in interest over time, we have to bear in mind that, read as a whole, the figures are not quite so striking. The mean percentages are given in Table 1 below. As can be seen, the EC/EU ranks seventh in the list of mean percentages. Even if we limit ourselves to the period since January 1997, the period of the most consistently high percentages for EC/EU, it still only comes joint third in the ranking, after the NHS and education, at the same level as unemployment. 
Table 1

Mean Percentages for Issues Considered Important in the UK

\begin{tabular}{lcc}
\hline Issue & $\begin{array}{c}\text { September 1974- } \\
\text { September 2001 }\end{array}$ & $\begin{array}{c}\text { January 1997- } \\
\text { September 2001 }\end{array}$ \\
\hline Unemployment & 49.0 & 24.2 \\
NHS & 32.2 & 45.2 \\
Schools EO Education & 21.6 & 34.1 \\
Economy EO Economic Situation & 19.8 & 14.2 \\
Law Eं Order & 19.4 & 21.0 \\
Strikes EO Trade Unions & 18.7 & 0 \\
EC/EU & $\mathbf{1 2 . 8}$ & $\mathbf{2 4 . 2}$ \\
\hline
\end{tabular}

Source: MORI, http://www.mori.com/polls/trends/issues.shtml

From all of this, we can summarize that the EC/EU is not the dominant issue in British politics. In contrast to the lengthy and divisive debate by politicians and the media since the first membership application of 1961, it has only really been in the past four years that the issue has developed into a mass preoccupation, and even then less than a quarter of the population regards it as an issue of importance.

\section{COMPETING TENSIONS WITHIN PARTY STRUCTURES}

Looking at the previous sections, there are clearly two competing tensions at work. On the one hand, the electoral system in the UK pushes apart party positions on European integration and raises its profile. On the other, since voters do not place the matter very highly on their list of priorities (with the possible exception of the last four years), there is a danger that by fixating on 'Europe' as a defining issue parties will discourage the support of voters, particularly with respect to other issues. The problem essentially comes down to how these two separate effects can be balanced to a workable equilibrium point.

In a two-and-a-half party system such as the British one, it is clearly important for party managers to maintain party cohesion. Governments are almost always formed by a single party, so issues of coalition management are internalized within the party structure. This requires some attempt to take policy lines with which the vast majority of party members, and all MPs, can work. 
Naturally, it is not possible to accommodate fully everyone's position on every policy field. However, since different policy fields are given different levels of importance, individuals are prepared to compromise on (for them) minor issues in exchange for accommodation on more important points. And it is this that creates the conflict with public opinion, since politicians' minor issues are increasingly likely to be voters' major concerns. As we have seen, the general public has not matched the level of interest and conflict over European integration that political parties have achieved both between and within themselves. ${ }^{20}$

The relative over-emphasis by politicians on European affairs results in an under-emphasis on other issues that the general public hold to be more important. There are thus potential implications for voter intentions, since if we assume that voters choose parties that most closely match their personal preferences, then the effect described above will reduce that match. ${ }^{21}$ This then becomes the central balancing act that party managers have to deal with: shortterm management of party cohesion to ensure effective parliamentary majorities against longer-term vote maximization.

\section{RESOLVING THE TENSIONS}

Faced with this tension, party managers have traditionally been left with one of two options. They can either try to actively manage policy outcomes or they can fudge them. This statement requires further explanation.

By actively managing policy outcomes, party managers try to resolve the tension by modulating the balance of policy over electoral cycles. During the start and middle of the cycle, when Parliament is relatively isolated from electoral pressures, managers might tend to favour policy positions further from public opinion, before moving

${ }^{20}$ As Rasmussen notes, for all of Thatcher's clear opposition in the late-1980s, there was no transmission of those views to the general public. J. Rasmussen, 'What Kind of Vision is That? British Public Attitudes towards the European Community During the Thatcher Era', British Journal of Political Science, 27:1 (1997), pp. 111-18.

${ }^{21}$ Clearly voter intention is not just about personal preferences, most notably with the rise of tactical voting, as typified by the 1997 General Election. 
back again in time for elections. This they would do by a variety of means. A first effort would be to remove temptation by organizing parliamentary time so as to avoid an election taking place at the same time as a relatively important policy development. This is somewhat curtailed by the European calendar, over which domestic politicians have only limited control. A second strategy works around the offering of inducements in other policies to extreme party elements in exchange for a moderation of their position on European integration. This clearly depends on the relative importance of the European issue, the margin of manoeuvre in the other policy fields and the relative power of the extreme elements. The third and most extreme option is to threaten extreme elements with exclusion from the party if they do not moderate their opinions. While this might preserve party cohesion, it does not help parliamentary business, nor does it convey an impression of a united party to the voting public. ${ }^{22}$

Seen as such, the active management option appears to be fraught with dangers and the alternative, fudging, becomes more attractive. Here, rather than attempting to position the party accurately within its members' opinions and those of the public, party policy becomes flexible enough to accommodate most, if not all of them. This works across several points of the electoral cycle. Policy commitments (such as in manifestos) are couched in terms which leave a certain amount of interpretation by the party, or which leave open escape routes. In Parliament, votes on different elements of European policy are subject to differing levels of whipping. Contentious decisions can be masked by timing them to coincide with other policy initiatives or events. Finally, in the run-up to elections, party leaders can modify their positions when addressing different audiences. In its most extreme form, fudging simply means avoiding the issue completely, by not producing any policy position at all, at least until the conditions become more favourable. In so doing, the party gains a flexible position on European affairs, within which short-term conflicts and tensions can be ridden out.

Naturally, there are elements of both active management and fudging in most parties' policy-making; it would be an incautious party that let itself be boxed in. However, since neither strategy can

${ }^{22}$ See G. Evans, 'Euroscepticism and Conservative Electoral Support: How an Asset Became a Liability', British Journal of Political Science, 28:4 (1998), pp. 573-90. 
result in a complete and persistent representation of all the positions on European affairs there remains a tension. This tension could be resolved by a split in the party, but with the likely consequence of an exclusion from office. Hence other strategies have to be found. The most important of these is an externalization of the debate on European integration.

Sitting outside the set of formal institutions, we find groups, organizations and movements that bring together elements of political parties and the general public. Free from the constraints of seeking electoral success, these groups can adopt whatever structure and positions they feel best represent their interests and priorities, since that is their primary purpose. It is this freedom that offers a potential solution to the tensions we have discussed so far. Moreover, the liberty to construct a discourse on membership based around clear costs and benefits to the public - rather than the necessarily more vague party lines - creates the potential for these groups to have a greater impact on public opinion.

By taking a permissive approach and letting those who have strong views on the matter of European integration express them through the alternative outlet of non-party groups, party managers can potentially reduce the tension within the party on policy positions, at least in the short term. Similarly, non-party groups offer those extremists the opportunity to give full vent to their feelings, without jeopardizing their position within the party structure. Certainly, since the ultimate aim of any non-party group is to change public policy outcomes, there is still a conflict between the governing party and those members of that party involved in non-party group activity. However, that conflict is, crucially, externalized.

We note here that the permissiveness of party managers can be broken down into voluntary and involuntary parts, the latter being more common. At points such as the 1975 referendum, the use of a free vote allows party managers to sidestep any internal division on a high profile decision, often on the basis that the loss of opposing elements from within the party will be more than balanced out by the gain of support from other parties. However, aside from these key points (of which a future referendum on the euro could well be one) the everyday nature of European decision-making makes free votes impractical, and the use of whipping is required. But as we have already noted, the smaller the government's majority, the greater the relative power of individual members and the more likely it is 
that they will challenge the Whip. Since that challenge has to be tempered by the desire to be returned at election time and hence the need to retain membership of the party, individuals wanting to express their opposition will limit their intra-parliamentary activity and move outside. This is clearly a matter that party managers would have difficulty controlling, even if they wanted to, which we have argued they do not.

Since non-party groups are not just composed of marginal members of political parties, but also of non-party political figures, the 'party political-ness' of the groups is obscured and reduced. This is also apparent in the creation of cross-party groups, which further limits the association between a group and a party. However, some distinction should be made between non-party groups and groupings within parties on specific issues. This latter set - typified by such bodies as Conservative Way Forward, Conservatives Against a Federal Europe and the Labour Euro-Safeguards Campaign - are a means of organizing party factions within the party structure, although some have developed links beyond the parliamentary party. While such groups play an interesting role in the development of parties' policy outcomes, they are still essentially held hostage by the tensions of party cohesion and vote-maximization. Hence we shall concentrate on non-party groups. Figure 3 (p. 224) gives the foundation dates of the more notable groups.

The UK has a long history of anti-European non-party groups, reaching back to the early 1960s. Of these the most important was Keep Britain Out, which was a key player (under the name Get Britain Out) in the 1975 referendum, along with the Labour-oriented Common Market Safeguards Campaign (later the Labour European Safeguards Campaign). ${ }^{23}$ The National Referendum Campaign, the umbrella organization under which these and several other groups worked, broke up straight after the referendum, with some groups becoming involved in the Safeguard Britain Campaign (later the Campaign for an Independent Britain).

Conditions in the 1970 s were relatively conducive to such protest groups: neither the Conservatives nor Labour had large parliamentary majorities in the 1970s; there was a key decision on membership to be made; public opinion was relatively interested in European affairs and support for membership was weak (the referendum result

${ }^{23}$ See D. Butler and U. Kitzinger, op. cit., pp. 97-115, for a detailed account of the No campaign and its constituent elements. 


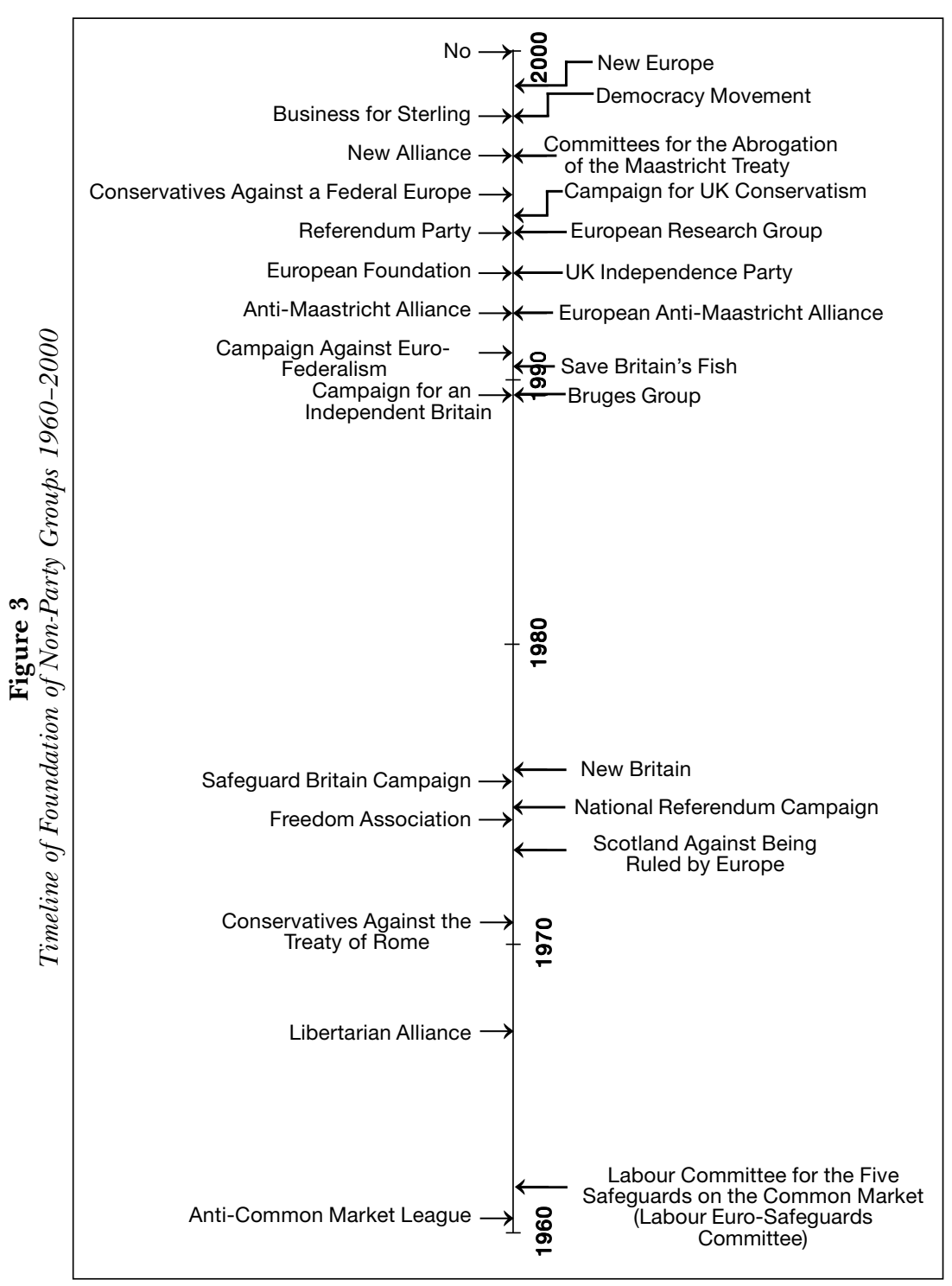


notwithstanding). But after 1975 those conditions were to disappear one by one. It was only in the late-1980s that there was a rebirth of non-party activity.

The turnaround in Thatcher's European policy after the SEA, most famously made in her Bruges speech of 1988 (which led to the creation of the Conservative Bruges Group), marked the beginnings of a new wave of opposition to integration. Conflict within the Conservative Party came to a head after the 1992 general election, when the so-called Euro-sceptics could lever the small parliamentary majority. The sceptics had the ideal opportunity with the TEU ratification procedure, resulting in a bitterly fought contest. ${ }^{24}$ In the aftermath of the TEU ratification, new groups were set up to channel opposition into the political system (notably the European Foundation, created by Bill Cash in 1992), drawing in primarily Conservative Party members and voters.

While the 1997 Amsterdam Treaty did not result in similar reactions, membership of the single currency became increasingly important to opposition groups, despite the British opt-out clause. Increasingly vocal elements within the Conservative Party calling for a principled 'never' on joining EMU, coupled with the high-profile protest party of Sir James Goldsmith, the Referendum Party, produced an extra hurdle to that membership. While the Referendum Party had no appreciable effect on the election result, it did result in both the Conservatives and Labour committing themselves to a referendum on entry into stage three.

As a referendum on the euro became a certainty, so those against the euro began to focus on organizing their campaign. In 1998 Business for Sterling was created as a forum for businessmen by the former Labour transport minister, Lord Marsh. Like its political counterpart, Lord Owen's New Europe group, Business for Sterling has been careful to distinguish itself from anti-EU groups, proclaiming itself to be against merely the euro, rather than the EU as a whole, although there is still some contact with the irredentist UK Independence Party and others. ${ }^{25}$

${ }^{24}$ D. Baker, A. Gamble and S. Ludlam, 'The Parliamentary Siege of Maastricht 1993: Conservative Divisions and British Ratification', Parliamentary Affairs, 47:1 (1994) pp. 37-60.

${ }^{25}$ Interview with UKIP secretariat official, Sept. 1999; interview with Business for Sterling secretariat official, Sept. 1999. The former described contact as 'passive'. Also see http://www.bfors.com/ and http://www.new-europe.co.uk. 
This brief overview of the development of the anti-European movement in the UK has highlighted several points. First, the development has been driven much more by political dissent than by public disquiet. This is apparent in the large number of groups being formed from 1992, at the time of the Maastricht ratification process, when public opinion was at a high point of support for membership and did not rate the matter to be very important (see Figure 1). In being driven by political dissent the anti-European movement closely follows the pattern of tensions within the party political system, particularly the development of the deep split in the Conservative Party.

Secondly, a distancing between individual groups and parties has taken place. No one group has unreservedly linked itself to a single party, even when the vast majority of its members belong to, or vote for, such a party. ${ }^{26}$ The appeals to cross-party support, or an 'apolitical' position, are frequent.

Thirdly, externalized groups have played an important function as entrepreneurs of contentious issues. Given their aim of expressing opposition, they have somewhat paradoxically become close and knowledgeable observers of the EU system, a position that has seen them directing attention to developments before anyone else. Current examples include concerns about the development of a European law code and the regionalization of England, which have been trailed for several years by various groups. ${ }^{27}$ Thus, as well as promoting an oppositional viewpoint on integration, these groups have been able to set the agenda of political and media discussion to a notable degree.

Fourthly, it is apparent that only in very rare cases have antiEuropeans managed to hold together a united front towards others; much of the history of the differing groups has been marked by infighting and splits. However, while the organizations and groups might change, it is also apparent that the individuals crop up again and again. This continual change and mutation of organizational forms reflects the diversity of the backgrounds of those opposing

${ }^{26}$ This is true even for groups with roots within parties, such as the European Foundation (http://www.e-f.org.uk/).

${ }^{27}$ For Corpus Juris see http://www.keele.ac.uk/socs/ks40/art.htm for various links. For regionalization see The Freedom Association's newsletter from October 1999 http://www.tfa.net/ft/bypass.htm or a piece from the UKIP's Comment section at http://www.ukip.org/html/bodycomment12.html. 
European integration and the problems of finding common ground beyond that simple opposition.

However, at a more systemic level, there are more pressing concerns, particularly from the viewpoint of party managers. These concerns relate to the long-term costs of externalizing the European debate from party structures, which have to be set against the beneficial short-term effects.

\section{CONSEQUENCES}

As we have seen, externalizing the debate on European integration helps party managers to reduce intra-party tensions and so reduce the potential loss of votes. However, it is also clear from our brief survey of non-party groups that this cannot be a long-term solution.

Externalization works because it removes the vote-maximization and re-election constraint from those elements that are in most tension with the party leadership. However, in freeing themselves from that constraint, they serve to increase the potential for a radicalization of positions. To explain this we need to return to Aspinwall's model. As he states, the structure of the British electoral system excludes the more dogmatic elements at the first hurdle election to parliament - so that they tend not to attain a position of power for opposing the EU. ${ }^{28}$

However, Aspinwall's model does not address the consequences of externalization of tensions into non-party groups. Outside party structures, and through the construction of non-party groups, those on the fringes of parties can establish links with elements holding even more extreme views. This effect is demonstrated in Figure 4 below. While the party accommodates a relatively large range of positions on European integration, the non-party groups by definition have a much smaller range. However, that range still pulls the median point of the positions sharply over towards the opposition end of the scale (i.e. from M1 to M2).

The consequence is a general radicalization of the opposition towards European integration. Through exposure to more extreme elements, we might suggest that those parliamentarians who work with non-party groups further out on the fringes of the spectrum of

${ }^{28}$ M. Aspinwall, op. cit., p. 431. 
Figure 4

The Centrifugal Effect of Externalization

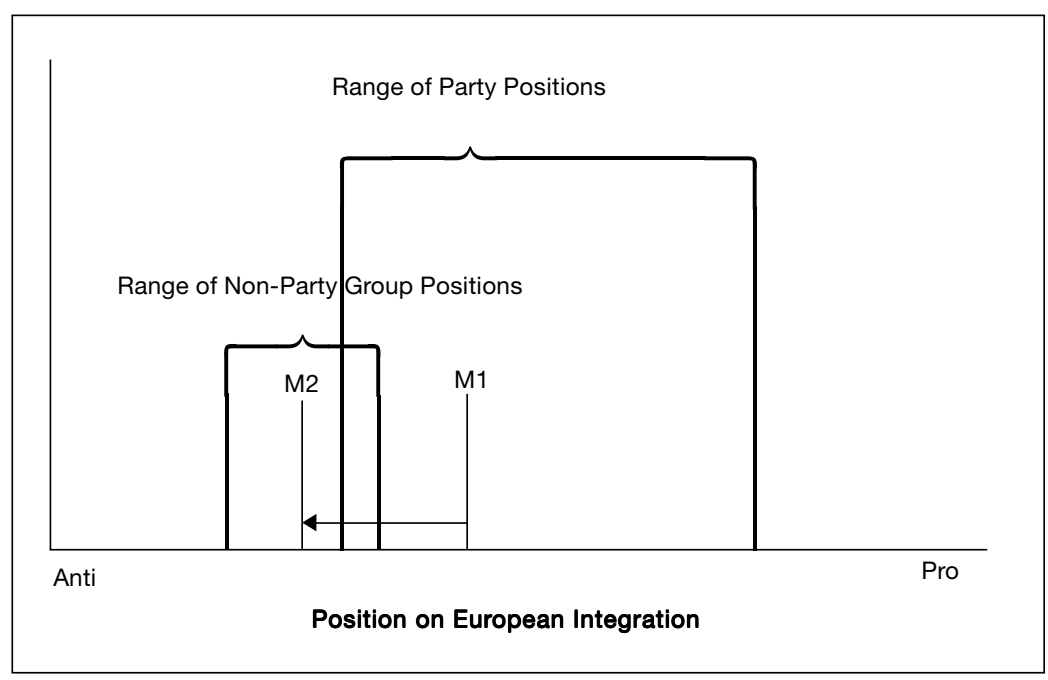

opinion become more confirmed in their views and so drift further away from the party line. This process is facilitated by the relatively dense network of contacts and groupings within the anti-EU fringe. Since opposition lies at the fringes of the political spectrum, this effect also opens up an indirect access route to influencing policy outcomes for groups that would otherwise be totally excluded. The travails of the UKIP and its infiltration by elements of the British National Party represent the more extreme version of this process, but it is also to be found in the tension that besets anti-EMU groups like New Europe and Business for Sterling, which have difficulty in limiting their opposition to just the one project. ${ }^{29}$

As much as externalization reduces party tension in the short term, in the longer term this effect of radicalization feeds back into the political scene with a pressure-cooker effect. The radicalization that we see eventually pulls the anti-integration wings of the parties further

${ }^{29}$ See A. Sked, 'Sceptics Who Betray Britain', The Spectator, 10 February 2001, for more on UKIP. The pro-European Britain in Europe has been keen to point out the inconsistencies of New Europe and Business for Sterling's positions (http:// www.britainineurope.org/). 
down that path, so increasing the distance within the party between the pro- and anti-wings. As was evident in the Major administration of 1992-97, this heightened public confusion over the party's stance on European integration and contributed to its downfall in the 1997 General Election. ${ }^{30}$ In the run-up to the 2001 General Election, the strength of the anti-European wing of the Conservative Party resulted in a concerted effort to minimize the influence of the pro-wing, through the selection of parliamentary candidates who held positions even more extreme than the official party line.

Furthermore, the externalization process can have effects on the entire political spectrum, as was seen in the 1997 General Election. The Conservatives offered a referendum on the single currency as an attempt to limit the potential damage that internal dissent in the party, not to mention the Referendum Party, might have on their support. This in turn forced Labour to offer the same, since it could not afford to lose votes on the issue, either from disaffected Conservatives or from Labour voters who wanted a voice on the matter. The entire system thus moved towards a more sceptical position, since any referendum would mean confronting a steady deteriorating base of support for membership.

\section{CONCLUSIONS}

While Aspinwall's model provides us with a very useful starting point for a discussion of the pattern of opposition towards the European Union in the UK, it does not give us a complete picture. The tensions that build up both within parties and between parties, and relative public indifference, have to be resolved by some means. Active management and fudging strategies by party managers, which have traditionally been used to mediate these conflicts, have proved inadequate to deal with the particular nature of the European issue. In this way, externalization of the tensions becomes an increasingly attractive option, both for the party managers and for those elements

${ }^{30}$ G. Evans, 'Euroscepticism and Conservative Electoral Support', op. cit., shows how even though the Conservatives had the aggregate position on Europe closest to the public's, on an individual level those who were pro-European saw the party as anti-European, while anti-Europeans thought it to be pro-European. This effectively negated any benefit of its drift towards Euro-scepticism. 
within parties that feel poorly represented. The history of the UK's membership of the European Union has seen the creation of various groups which bring together both the disaffected political elements and members of the wider public. The initial wave of groups at the time of the 1975 referendum was quickly dissipated and it was only in the late-1980s, and particularly after the Maastricht Treaty of 1992, that groups developed in any quantity. By the end of the 1990s, these groups had become numerous, well resourced and well connected in comparison to any pro-European network, and were increasingly influential on party politics. In this, they were demonstrating the long-term costs of externalization, namely increased party tensions and a shift in public attitudes.

Given that such non-party groups have continued to proliferate, we might expect these dynamics to persist, at least in the short term. Certainly, the outlines of the 'Yes' and 'No' campaigns for the referendum on membership of the euro were put in place from 1998 onwards, with the creation of Britain in Europe and New Europe respectively. Both Labour and the Conservatives have already indicated that these will be at the heart of their campaigning, rather than going for a straight party-based competition. This not only allows for the building of cross-party support, but also limits to some extent the potential damage caused by losing. This process runs parallel to the processes we have discussed in this article, but it also interacts with them, as the two central groups build wider organizational nets. As a consequence, if we are to have a full understanding of the story of any forthcoming referendum, then we must look beyond pure party politics, to the wider field of civil society and the role of nonparty groups. 